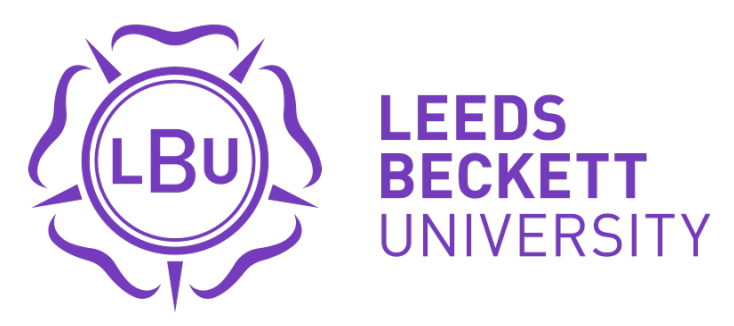

Citation:

Feletti, F and Brymer, E (2018) Pediatric and Adolescent Injury in Skateboarding. Research in Sports Medicine, 26. ISSN 1543-8627 DOI: https://doi.org/10.1080/15438627.2018.1438285

Link to Leeds Beckett Repository record:

https://eprints.leedsbeckett.ac.uk/id/eprint/4833/

Document Version:

Article (Accepted Version)

This is an Accepted Manuscript of an article published by Taylor \& Francis in Research in Sports Medicine on 24 April 2018.

The aim of the Leeds Beckett Repository is to provide open access to our research, as required by funder policies and permitted by publishers and copyright law.

The Leeds Beckett repository holds a wide range of publications, each of which has been checked for copyright and the relevant embargo period has been applied by the Research Services team.

We operate on a standard take-down policy. If you are the author or publisher of an output and you would like it removed from the repository, please contact us and we will investigate on a case-by-case basis.

Each thesis in the repository has been cleared where necessary by the author for third party copyright. If you would like a thesis to be removed from the repository or believe there is an issue with copyright, please contact us on openaccess@leedsbeckett.ac.uk and we will investigate on a case-by-case basis. 
Pediatric and Adolescent Injury in Skateboarding

Special Issue: Kids in Adventure and Extreme Sports - Too Risky?

Feletti, $\mathbf{F}^{1,2}$ and Brymer $\mathbf{E}^{3}$

${ }^{1}$ Local Health Trust of Romagna, Department of Diagnostic Imaging, S. Maria delle Croci Hospital, Ravenna, Italy

${ }^{2}$ Department of Electronics, Information and Bioengineering, Polytechnic University of Milan, Italy

${ }^{3}$ Institute of Sport Physical Activity and Leisure, Leeds Beckett University, UK

Running head: Injuries in Skateboarding in the Paediatric Population

\section{Contact information}

Francesco Feletti

E-mail: feletti@extremesportmed.org 


\title{
Pediatric and Adolescent Injury in Skateboarding
}

\begin{abstract}
Skateboarding has become an international action sport attractive to young people. For this reason, skateboarding has been promoted by some researchers as important for encouraging young people to become more physically active. However, skateboarding is also considered to be inherently dangerous by the medical and broader community and as a result skateboarding is banned in many places. This paper reviews scientific literature on the features, outcomes and risk factors related to skateboarding injuries. Findings suggest that while skateboarding injuries can be severe, skateboarding is not as dangerous as it might appear if appropriate risk management steps are taken. Skateboarding should be encouraged as a worthy physical activity and local communities should consider providing specialised, supervised spaces for young people to practice this sport.
\end{abstract}

Key words: Skateboarding, pediatric, adolescent, injury 


\section{Introduction}

Skateboarding is an international sport with a variety of competitive and non-competitive subdisciplines (e.g. mountain boarding, longboarding, street and freestyle) (Hunter, 2012; McKenzie, Fletcher, Nelson, Roberts \& Klein, 2016). Like all adventure and extreme sports (AESs) skateboarding has not been constrained by the structures that guide traditional sports, and has developed organically and often chaotically to become a worldwide phenomenon (Immonen et al, 2017; Kellet \& Russell, 2009). The traditional notion that skateboarding was for young male hedonists is evolving and the sport is becoming more gender balanced, involving older participants, and less defined by hedonism and risk. An analysis of recent skateboarding statistics suggests that skateboarding is worth an estimated $\$ 4.8$ billion in annual revenue with 11.08 million active skateboarders in the world (https://www.shop-eat- surf.com/2009/05/the-state-of-the-skateboardingindustry; accessed on October 2017).

Skateboarding is particularly attractive to young people because it is not typically constrained by the artificial boundaries or rules found in traditional sports (Fig. 1,2) (Thorpe, 2016). In the US between $7.4 \%$ and $17.4 \%$ of school aged children (6-17 years) practiced skateboarding between 2006 and 2012 which equates to approximately 5.3 million participants/year (Outdoor Foundation, 2013). Similar statistics have been recorded in other countries (Australian Bureau of Statistics, 2011). From this perspective skateboarding has a potential role in the health and wellbeing of young people across the world. Recent statistics reveal low physical activity levels in young people linked to physical and mental health issues such as obesity and anxiety (Australian Bureau of Statistics, 2007; Kumanyika, Jeffery, Morabia, Ritenbaugh \& Antipatis, 2002). However, like other AESs, skateboarding has suffered from the perception that it is overly dangerous and skateboarding injuries are severe and life threatening (Kyle, Nance, Rutherford \& Winston, 2002). Consequently, skateboarding is often viewed negatively by the medical community and has been discouraged in many places around the world (Graham, 2010; Keays \& Dumas, 2014). This article 
reviews the epidemiology of pediatric and adolescent injury in skateboarding and suggests possible areas for further research.

\section{Please Insert Fig 1 and 2 about here}

\section{Methods}

The primary reference sources for this study were from the electronic database SCOPUS, the world's largest database of peer-reviewed coverage of Medline. The literature search was limited to published, peer-reviewed reports and involved the following search terms as well as extensive cross-referencing: skateboarding, injury, injury risk factors, and injury prevention. Only studies where it was possible to extract data relative to skateboarding for populations under 18 years have been included. The ancestry approach was used to garner additional citations for the review.

\section{Limitations}

Methodological limitations stemmed from population diversity in studies with respect to age, experience level, style and location of practice (e.g. streets, skate-parks). Different studies stratified age groups differently which created challenges when presenting data in a precise manner. In this review,age groups are: infants (<2 years), pre-schoolers (2-5 years), school-aged children $(6-11$ years), adolescents (12-18 years) (Knoppert et al, 2007). Injury definitions also varied across studies; for example, the definition of concussion and accompanying symptoms are still being debated (West \& Marion, 2014). A major limitation is that many studies were primarily hospital- or registry-based, limited to a single medical facility or trauma center and therefore not necessarily representative of all skateboarders. Also, the data on injuries are numerator-based and do not permit determination and comparison of injury rates both within and between studies. Finally, as with many AESs, skateboarding involves many variables, and research into accidents and injuries in 
skateboarding often used methodologies that failed to adopt multi-factorial approaches (Feletti, 2016).

\section{Who is affected by injury?}

Table 1 summarizes data on pediatric and adolescent on skateboarding injuries

Studies are mostly case series, reporting data from hospitals, existing public systems (e.g., NEISS in the USA) and trauma registries, either retrospectively or prospectively. However, cross-sectional and retrospective cohort designs are also included. As such, most injuries reported were acute in nature, ranging from minor cuts and abrasions to multiple fractures. Only a few papers documented rates of injury and these were reported relative to number of participants (Schuman, 1967), skatepark users (Everett, 2002), number of participants per year (Konkin et al., 2006; Rethnanm 2008), and number of children/adolescents/year (McKenzie et al., 2016). Only one study reported exposure-based injury rate (Feiler \& Frank, 2000). In the United States, it was estimated that 64,572 cases of pediatric and adolescent skateboarding-related injuries were treated in hospital emergency departments between 1994-2008 (McKenzie et al., 2016).

As shown in Table 1, the vast majority of pediatric and adolescent skateboarders $(68.1 \%$ $100 \%$ ) were male, In most studies where adult skateboarders were included, the majority of participants were children or adolescents (Birkhoelzer, Kirschner \& Schweikert, 1979; Feiler \& Frank, 2000; Forsman \& Eriksson, 2001; Hawkins \& Lyne, 1981; Keays \& Dumas, 2014; Kyle et al, 2002; Lustenberger et al, 2010; Morgan, Galloway \& Patel, 1980; Rethnam, Yesupalan \& Sinha, 2008; Retsky, Jaffe \& Christoffel, 1991; Vaca, Mai, Anderson, Fox \& Ferrarella, 2007).

[Please insert Table 1 about here]

\section{Where does injury occur?}




\section{Anatomical location}

A summary of studies providing data on anatomical location of injuries is provided in Table 2. Skateboarding injuries most often involved upper limbs (Range $=22.8-77.2 \%)$, followed by lower limbs (Range $=13.9-44.6 \%)$. Trunk and head injuries are less common but may be severe, including spinal and internal organs injuries (Campodonico, Paparo, Calcagno, Capponi \& Conzi, 2016; Cass \& Ross, 1990; Kruse, 1990; Lustenberger, 2010; McKenzie et al, 2016; Pendergrast, 1990). Most upper limb injuries were distal radius fractures, hand fractures and soft tissue injuries

of the wrist. Rethnam et al. (2008) detemined that these three categories of injury account for 72.2 $\%$ of upper limb injuries.

Head injuries, account for approximately $3.5 \%$ to $9.9 \%$ of all skateboarding injuries (Fountain \& Meyers, 1996), and are more common among children under ten years old (McKenzie et al., 2016). Skateboarding induced head trauma often results from accidents at high speeds and patients who present with mild traumatic brain injuries (mTBI) may have more significant injuries, such as skull fractures or subdural hematomas (Bramley et al., 2014).

Thoracic and abdominal injuries are uncommon (Kruse, 1990; Schmid \& Rotzscher, 1993). However, a study by Lustenberger et al (2010) found that $4.0 \%(n=90)$ of skateboarders suffered a splenic injury, with surgical intervention required in $10 \%(n=9)$ of cases.

The lower limbs are involved in $18.1 \%$ of injury cases in the 5-10 age group. This percentage increases with age to $29.6 \%$ in 11 -14-year-old participants and $42.1 \%$ in 15 -19-year-old skateboarders (McKenzie et al, 2016). Injury distribution depends on several factors, including regular (skating with left foot forward) or goofy (skating with right foot forward) stance, where the right side of the body is most commonly injured among those who use the goofy stance (Keilani et al, 2010).

\section{Enrironmental location}


Skateboarding is generally practiced in urban settings and often within densely populated residential areas, including school yards, public roads, market places, court yards, and parking areas. However, dedicated skate parks also exist in many countries. Children less than ten years old most commonly incur skateboarding injuries at home (51.9\%), while older children are more likely to be injured on the street or in sports places (52.9- 61.2\%) (McKenzie et al, 2016).

Some studies conclude that skateboard-related injuries, between $38 \%$ and $62.5 \%$, are more likely to result from activities in spaces shared by motor vehicles, such as roads or parking lots, in contrast to 8-26.4\% happening in skateparks (Hawkins \& Lyne, 1981; Keays \& Dumas, 2014; Osberg, Schneps, Di Scala \& Li, 1998). However, according to Forstman and Eriksson (2001), most injury events take place at skateboarding areas. One study reported that skateboard-related pediatric admissions increased when a new skate park was opened (Sheehan, et al, 2006). Research examining injury patterns in skate parks for children (7-18 years) show that areas with ramps or bars were three times more likley to be responsible for injury events than gully areas and about six times more than half-pipe areas (Schalamon, 2003).

\section{Special consideration related to skate parks}

Commercial skateboarding parks are generally controlled, large, well lit, enclosed or semi-enclosed structures routinely maintained by on-site staff who also supervise and monitor the park and participants. Parks do not suffer from externalities such as motor vehicles and pedestrian traffic, or obstacles and irregular surfaces such as potholes. Furthermore, commercial skateboarding parks typically require athletes to wear safety equipment such as helmets and knee and elbow pads (Everett, 2002). Nevertheless, injuries may be more frequent in skate parks (Forstman \& ???, 2006) because they might create a heightened sense of competition among skaters, and riskier skateboarding styles (Everett, 2002). In addition, skate park design may enable expert participants to reach high speeds and perform acrobatic stunts which may increase the risk of severe injuries (Sheehan, et al, 2006). 


\section{When does injury occur?}

\section{Injury onset}

Skateboarding often involves repetitive movements, repetitive training and competition with little regard for recovery, potentially leading to overuse injuries, including elbow edema with arthralgia, ulnar nerve compression and neuritis (Nathanson, Ribeiro \& Henneman, 2016; Norkus \& Meyers, 1994; Patel, Greydanus \& Baker, 2009). In one study overuse injuries represented $12.5 \%$ of skateboarding injuries for 5 to 17 year olds (Stracciolini, Casciano, Friedman, Meehan \& Micheli, 2015).

\section{Temporal Variations}

Skateboarding is a demanding recreational activity which is mainly practiced on weekends, with little weekday practice. This might result in higher rates of severe injury (Roberts et al, 2014). However, it is hard to draw conclusion as data on seasonal and/or other temporal variation in skateboarding injuries are missing in many studies (Hunter, 2012). A study undertaken by Rethnam et al. (2008) indicated that $72 \%(n=36)$ of reported injuries took place during the summer; this may be because favourable weather conditions encouraged increased practice of this outdoor sport.

From 1990-1994 the annual rate of skateboarding injuries per 10,000 US children/adolescents significantly decreased for all age groups, and then significantly increased from 1994-2008 (McKenzie et al., 2016). The decreased injury rates during 1990-1994 were significant for males only. However, during 1994-2008 the annual rates of injuries significantly increased for both males and females (McKenzie et al., 2016)

\section{What Is the Outcome?}




\section{Injury Type}

Injury type for skateboarding in pediatric populations has been reported in several studies as shown in Table 3. Fractures were common, ranging between $29 \%$ and $61 \%$ of skateboarding injuries (Finch, 1998), while sprains and strains are more frequent than lacerations or contusions in most of the series (Forsman, 2001; McKenzie et al., 2016). When treating children with hand pain after skateboarding falls scaphoid fractures, an otherwise unusual child fracture, should be considered, because of the risk of pseudarthrosis as a result of a misdiagnosis (Brudvik, 2001).

Please insert Table 3 about here

Concussion was diagnosed in 3-5.3\% of injuries (Forsman \& Eriksson, 2001; Illingworth, Jay, Noble and Collick, 1978; McKenzie, 2016). In the US, between 2001-2005, there were 4,647 emergency department examinations for skateboarding-related concussions in 8-13 year olds; this represented $4.5 \%$ (CI: 95\%) of all sport-related concussions. In 14 to 19 year-olds there were 4,403 skateboarding related concussions, which represented 2.9\% (CI: 95\%) of all sport related concussions (Bakhos, Lockhart, Myers \& Linakis, 2010).

\section{Physeal fractures}

As shown in Table 3, msost reported skateboarding injuries in children were fractures. The risk of fracture is amplified in school-age and pre-school children because of incomplete epiphyseal plate closure. These fractures may result in impaired further bone growth (Cox, Thambapillay \& Templeton, 2008; Fountain \& Meyers, 1996). Two studies specifically reported the physis in skateboarding-related fractures (Banas, Dalldorf, \& Marquardt, 1992; Zalavras, Nikolopoulou, Essin, Manjra \& Zionts, 2005). Nevertheless, Zalavras et al (2005) found that the physis was involved in $33 \%$ of fractures, while according to Banas et al. (1992), epiphyseal fractures occurred in $42 \%$ of skateboard accidents involving skeletally immature participants. Furthermore, $22 \%$ of physeal 
fractures were displaced, mainly involving the distal radius (57\%), the distal tibia (29\%) and the distal fibula $(14 \%)$ (reference)

Salter Harris fractures complicated by compartment syndromes and requiring emergency fasciotomy have also been reported in young skateboarders (Birkhoelzer, 1979). Complex forearm skateboarding injuries may require open reduction and internal fixation even in children (Bauer \& Kiefer, 1991). In this respect, Sheehan et al. (2003) reported that skate parks encompass an increased relative risk of 8.35 for fractures requiring manipulation or invasive orthopaedic treatment.

\section{Injury Severity}

The severity of skateboarding injuries retrieved by the National Paediatric Trauma Registry, (19881997) was as follows: $5.5 \%$ trivial (Injury Severity Score (ISS: 0-3), 44.5\% minor (ISS: 4-8), 33.5\% moderate (ISS: 9-15), 10.2\% severe (ISS: 16-24) and 6.3\% critical (ISS: 25-75) (Osberg et al, 1998). Forsman and Ericksson (2001) reported only minor and moderate injuries (ISS: 1 - 2).

In two national studies of US emergency department skateboard injuries, children and adolescents requiring hospital admission ranged between 2.7\% and 3.1\% (Nathanson, et al, 2016; McKenzie et al. 2016). Young male skateboarders are more likely than females to require hospitalization, possibly because they perform more challenging manoeuvres (Kern et al, 2014). Hospitalization is more likely to have resulted from collisions with motor vehicles (crude odds ratio: $11.4 ; 95 \% \mathrm{CI}, 7.5,17.5)$ (Kyle et al, 2002). The mean length of hospital stay (LOS) among 254 children/adolescents (<19 year-old) from skateboarding-related acute injury was 6.0 days (Osberg et al, 1998). In a study on skate parks in California, skateboarders younger than 18 years old had a mean time loss of 2.0 days from school per skate park-related injury (Vaca et al, 2007).

\section{Clinical Outcome}


Lustenberger et al. (2010) determined that the incidence of severe trauma (ISS $>/=16$ ) was $5.4 \%$ for those younger than ten years; and $13.5 \%$ in the 10-16-year group, with life-threatening skateboarding-related injuries not uncommon. The authors reported a fatality rate of zero for those under ten years, and $0.3 \%$ in 10-16 year olds. Based on a study of 56,362 injured skateboarders Retsky et al. (1991) found that only a few fatalities involved children $(5.26 \% ; n=2)$ while $81.5 \%$ $(n=31)$ of the reported deaths were among adolescents. A Canadian study reported nine catastrophic injuries, including one fatality, for the 10-20 age group during what period? (Tator, 2008). Head injuries and spine injuries were the primary cause of reported fatalities, mainly from incidents involving motor vehicles (Lustemberger et al, 2010; McKenzie et al., 2016; Pendegrast, 1990; Retsky et al., 1991; Tator, 2008).

\section{Economic Cost}

The cost of treating skateboard injuries is high given the number of injuries presented to emergency departments (ED). In the United States an average of 64,572 cases per year were treated in EDs between 1994 and 2008 (McKenzie et al.,, 2016). Skateboarding related injuries in children have both a medical and indirect cost in terms of lost earnings for families (Vaca et al, 2007). In their study on the economic impact of skate park related injuries, Vaca et al (2007) found that each pediatric skate park related injury resulted in a mean medical cost of $\$ 1,516$. Moreover, each injury resulted in parents losing an average of 1.1 working days, corresponding to an average lost earnings cost of \$146 US. The total cost for each skate park related injury in children, including lost earnings and lost household production on the part of the injured parties, was $\$ 2,049$. However, the vast majority of lost time and incurred costs were suffered by a small group affected by the most severe injuries (Vaca et al, 2007).

Macdonald, McGlone, Exton and Perry (2006) found an increase in skateboarding related injuries following the opening of a skate park near their hospital and estimated the cost of treatment for these additional injuries to be $£ 60,134 /$ year. This is probably an underestimation of the total 
societal cost of these injuries as possible economic consequences from loss of earnings or long-term morbidity was not considered.

\section{Risk factors}

\section{Intrinsic Risk Factors}

Age, gender and personal habits, including the tendency to experiment with freestyle manoeuvres or alcohol consumption, may represent intrinsic risk factors for young skateboarders.

Age

According to McKenzie et al (2016), children 11-14 years of age represented the majority (44.9\% ; $\mathrm{n}=13,825)$ of children/adolescents treated in EDs for skateboarding related injuries. This group were also more likely to require hospitalisation compared to younger children [OR: 1.42 (1.171.73)], while older and younger children/adolescents had similar odds of hospitalization [OR: 1.09 $(0.89-1.33)]$

Injury distributions across different age groups are diverse, possibly because different stages of physical and psychomotor development may affect both injury biomechanics and risk exposure (Retsky et al, 1991). In children 5-10 years of age, cyclical periods of femoral growth lead to a high centre of mass which might reduce stability (Boyle, 1995), thus resulting in more injuries to the face (McKenzie et al., 2016). In 10-14 year old children, significant differences in coordination may reduce safety margins which may result in more fractures, especially to the upper extremities (McKenzie et al., 2016; Schuman, 1967) and in a significantly higher incidence of injuries to the spleen than those aged under 10 years (5.1\% vs. $1.1 \%$, p: 0.003) (Lustenberger et al, 2010). 
Finally, adolescent skateboarders may sustain the most lower extremity injuries (McKenzie et al., 2016) and may suffer more severe injuries because they attempt more hazardous manoeuvres at an age when the neuromuscular system is generally still undeveloped and they have poor agility, slow response times and limited proprioception (Fountain \& Meyers, 1996). The incidence of severe and critical injuries for those older than 16 years was significantly higher than in younger than 10 years (OR: 5.41, 95\% CI: $2.80-10.46$, p: 0.001, and OR: 4.23, 95\% CI: $1.31-13.72$, p: 0.009, respectively). Lustenberger et al (2010)

\section{Gender}

The risk of hospital admission for males was found to be almost double than for females (OR = 1.94; 95\% CI $=1.68-2.24)$ (Nathanson et al, 2016). In particular, older teenage males (average age 17.5 years) with advanced skateboarding experience may suffer more severe injuries. For example, being male represented a predisposing factor for severe traumatic brain injuries $(\mathrm{p}=0.018 ;$ AOR: 1.64) (Lustenberger et al, 2010).

The higher hospitalization rate in male skaters might be explained by their tendency to perform a wider selection of riskier manoeuvres due to recklessness and over-confidence. McKenzie et al (2016) reported that for females, as age increased, the proportion of injuries sustained at home decreased, while injuries sustained in the street and/or highway or sports and/or recreation places increased. Keilani et al (2010) found that experience, frequency of practice, and sociodemographic factors had no significant influence on injury frequency. Even sociodemographic factors such as unemployment and being single, which might influence the level of risk taken by adult skateboarders, did not show significant effects on the severity of injuries.

In the Californian series by Tominaga, Schaffer, Dandan, Coufal and Kraus (2015), alcohol use was reported among $18 \%$ of participants admitted for a skateboard injury to one Level II trauma centre; $24 \%$ of these for the $15-20$ age group despite the zero alcohol policies of that state. The 
authors recommended that skateboarding should be included among alcohol related recreational activities that result in head injuries.

\section{Extrinsic Factors}

Skateboards can reach high speeds, up to $40 \mathrm{mph}$ (Lustenberger et al, 2010), and the absence of any mechanical braking system may be a risk factor in skateboarding (Keilani et al, 2010). Prevention of skateboarding related severe traumatic brain injury includes helmet use ( $p=0.002$; AOR: 0.45$)$, skateboarding near home $(\mathrm{p}=0.001 ;$ AOR: 0.54$)$ or in skate parks $(\mathrm{p}=0.009 ;$ AOR: 0.70$)$ (Lusteberger et al, 2010).

Protective equipment such as wrist guards, elbow pads, knee pads, and helmets have influenced the risk of injury (Banas et al, 1992; Keliani et al, 2010; Lustenberger, 2010;). Sadeghian et al (2017) reported that not wearing a helmet in skateboarding resulted in a greater chance of head injury $(\mathrm{OR}=1.7)$ compared with wearing a helmet. However, reports suggest that $17 \%$ to $87 \%$ of children and teenagers, especially in certain at risk groups, do not use helmets or other protective equipment while skateboarding (Forjuoh, Fiesinger, Schuchmann \& Mason 2002; Keiliani et al, 2010; Provance, Engelman \& Carry, 2012; Sadeghian et al, 2017). In the USA, helmet use is lower in children older than age 12 years as compared to children age 12 years or younger, in boys vs girls, in ethnic and racial minorities (i.e. Asians, African Americans, Latinos and Native Americans) vs whites, and those who practice this sport in places other than skateparks (Sadeghian et al, 2017). Helmets are more likely to be worn in younger aged groups with, for example, a prevalence of $100 \%$ helmet use recorded for participants younger than 6 years (Forjouh et al, 2002). Those under adult supervision were 6 times more likely to use helmets than those skateboarding without adult supervision (Forjouh et al, 2002). While helmet ownership is common among schoolaged children (47\%), a study undertaken by Peachey, Sutton and Cathorall (2016), found that only 
$18 \%$ of those owning a helmet used it on their most recent ride. Reasons for not wearing a helmet included discomfort and vanity. The influence of family and friends encouraged helmet use (Peachey et al, 2016). Finally, skate parks can be safer than other public venues such as streets or urban structures, with no considerable difference between supervised and unsupervised skate park use (Dumas \& Laforest, 2009).

\section{What are the Inciting Events?}

Injury causing events are varied ( Table 3 ) but most likely to stem from a fall (Keays \& Dumas, 2014; Osberg et al, 1998). In infants and children, most injuries follow a loss of balance, failed trick attempt or an abrupt stop of the skateboard by an irregularity on the ride surface, projecting the skateboarder in the direction of travel (Forsman \& Eriksson, 2001; Fountain \& Meyers 1996; Gomez \& Rao, 2016; Keays \& Dumas, 2014; Macdonald, 2006). Plastic/bending fractures can occur when falling skateboarders brace themselves with an outstretched arm (Swischuk, 2015). For this reason, most injuries occur on the side of the leading foot. Since there are far more regular riders than goofy riders, most skateboarding injuries occur on the left side of the body (Shuman \& Meyers, 2015) or ipsilateral side of the leading foot. Other injury dynamics include the ankle getting stuck between skateboard and ground, collisions with motor vehicles, collision with a flying skateboard during an aerial trick and limb strains due to mismanaged execution (Forsman \& Eriksson, 2001; Gomez \& Rao, 2016; Keays \& Dumas, 2014; Rethnam, 2008). Equipment problems, fatigue and overuse may also cause or contribute to injuries (Nathanson et al, 2016).

Collision with other skateboarders is a rare cause of injury (1.4\%) (Konkin et al, 2006), collisions with motor vehicles may cause $2-24.8 \%$ of skateboarding related injuries (Osberg et al, 1998). Motor vehicle collisions resulted in $9.9 \%$ of severe injuries (Konkin et al, 2006) and may result in fatalities (Atienza \& Sia 1976; Cass \& Ross, 1990; Forsman \& Eriksson 2001; Shuman \& Meyers 2015; Retsky et al , 1991). 


\section{Injury Prevention}

The American Academy of Pediatrics recommended that children younger than 5 years should not practice skateboarding and that children between 6-10 years of age be closely supervised while skateboarding (Committee on Injury and Poison Prevention, 2002; Fountain \& Meyers 1996). Young participants should start by taking skateboarding lessons (Osberg et al, 1998) in order to acquire a reasonable skill level (Birkhoelzer et al, 1979). More specifically, children should learn how to fall (Pendergrast, 1990) and become confident with the rolling techniques that help reduce the risk of injury (Keilani et al, 2010). Furthermore, specific physical training could help improve neuromuscular control and so reduce injuries (Keilani et al, 2010). Other recommendations include carefully inspecting the board before using it (Pendergrast, 1990) and the adoption of technically high-grade equipment (Birkhoelzer et al, 1979).

The use of protective equipment, such as helmets, wrist guards and knee pads has also been recommended (Birkhoelzer et al, 1979; Everett, 2002; Forsman \& Eriksson, 2001; Lustenberger et al, 2010; Osberg et al, 1998; Pendergrast, 1990; Zalavras et al, 2005). Kumar, Herbst and Strickland (2012), found that helmets reduced linear head acceleration and head injury criteria, but had little effect on angular head acceleration. They determined that the risk of concussion, diffuse axonal injury and acute subdural hematoma remained high. Gum shield use has been recommended in order to prevent dentoalveolar injuries, and possibly also help prevent concussion (Everett, 2002).

Wrist guard usefulness is controversial. Studies on wrist guards using cadaver models indicate that they raise safety margins by augmenting the mechanical energy load capacity of the wrist (Greenwald, Janes, Swanson \& McDonald, 1998). However, biomechanical studies have not found any differences in fracture patterns with wrist guard use (Giacobetti et al, 1997). Elbow and knee pads may also attenuate skateboarding-related injuries (Lovejoy, Weiss, Epps, Zionts \& Gaffney, 2012). 
Another consideration is that participants may be reluctant to use protective gear for many physical, psychological and sociocultural reasons. A survey investigating personal protective equipment (PPE) under-use among 333 skateboarders with a mean age of 14.9 years found that the main reasons safety gear was not worn were: discomfort (68\%), lack of perceived need (40\%), appearance (21\%), cost (12\%) and non-use by friends (9\%) (Kroncke, Niedfeldt \& Young, 2008). PPE design is an important consideration. For example, helmet comfort requires the adoption of light hi-tech materials and a design that gives good peripheral vision without interfering with hearing. Using helmets (e.g. bike helmets) not designed for skateboarding may not be ideal. Equally participants may not consider helmets exclusively as a safety issue and may perceive helmet use as a form of control over their sport (O'Connor, 2016). Therefore, as this sport develops and is included among socially recognized activities, it is essential to promote helmet use from childhood onwards. For this reason, safety campaigns aimed at the pediatric population should address PPE under-use (Kroncke et al, 2008).

Since educational programmes, such as lectures, enactments of trauma and medical emergency procedures, have failed to modify participant attitudes toward injury prevention, it may be necessary to involve parents and teachers in pre-teen and adolescent neurotrauma prevention (Falavigna et al, 2014). Safety campaigns, aimed at both skateboarders and their parents, designed to raise awareness of risks and preventive measures, and increase the use of protective gear, have been proposed by some authors (Keilani et al, 2010; Nathanson et al, 2016; Osberg et al, 1998). Additionally, since the most common factor in equipment use was rules/requirement (46\%) (Kroncke et al, 2008), many authors have advocated the introduction of compulsory protective gear use (Keilani et al, 2010; Konkin et al., 2006; Osberg et al, 1998).

Providing designated skateboard areas (e.g. skate parks, multi-purpose paths and skatefriendly pedestrian ramps) and avoiding city streets (Pendergrast, 1990) may prevent collision with motor vehicles, thus reducing the risk of catastrophic events (Forsman \& Eriksson, 2001; 
Lustenberger et al, 2010; Osberg et al, 1998; Pendergrast, 1990). In this respect, skate parks can be seen as health-enhancing environments as they attract youths towards safe, active lifestyles, and encourage social interaction, socio-cultural integration and an informal coaching/learning process (Dumas \& Laforest, 2009).

\section{Further Research}

Establishing quality epidemiological research programs for skateboarding is particularly problematic. This is due to the large number of intermittent participants, the fact that they practice in many different locations and because young skateboarders may be reluctant to take part in medical research on account of counter-cultural habits. Further, assessment parameters adopted in traditional sports may be inadequate for skateboarding. In addition, this review showed that different pediatric age groups have different sport behaviour patterns, and this may be reflected in the different dynamics of trauma and the type and severity of sustained injuries. Researchers might need to focus on a specific age groups, and organized events could provide occasions to carry out cross-sectional studies and involve participants in cohort research.

Research programs designed to test risk factors for correlation or predictive value as well as the effectiveness of preventive measures are important, and depend on appropriate data collection. The importance of exposure-based data collection in obtaining an accurate picture of the incidence and characteristics of injury and as a basis for testing risk factors and evaluating preventive measures cannot be overestimated.

In addition to epidemiology, further research on the biomechanical aspects of skateboarding injuries and associated behavioural determinants are required (Vaca et al, 2007). Technology and 
ergonomics should collaborate in the development of comfortable, effective protective equipment, specifically designed for pediatric use. For example, the possibility of a fall impacting the parietal/temporal regions and of higher angular head accelerations should be taken into consideration in any further studies on protective headgear systems in skateboarding (Kumar et al, 2012). Similarly, manufacturers should develop special technologies to reduce peak pressures, high impact and shear forces in the forefoot, heel, and toe box regions (Determana et al. 2010). Research that helps improve skate park design is also important (Everett et al. 2002; Vaca et al. 2007); in particular, landing areas around ramps/bars where the highest-impact stunts and tricks are performed, and the most common site of injuries, should be examined with due care (Everett et al 2002). Studies designed to investigate the psychological and socio-cultural influences that encompass factors such as decision-making and the use of PPE should also be encouraged. In conclusion, however, while it is important to focus on injury epidemiology, skateboarding should be encouraged as it is a lifestyle sport that offers a fruitful strategy for involving more young people in active leisure (Dumas \& Laforest, 2009).

\section{Acknowledgements}

We want to acknowledge Nicola Debernardi, $\mathrm{PhD}$, research scientist at TNO (The Netherlands); photographer for Confusion Magazine, an international skateboarding magazine, he is also house photographer at Area 51 skatepark in Eindhoven, The Netherlands.

\section{References}


Atienza F, \& Sia C. (1976) The hazards of skateboard riding. Pediatrics. 57:793.

Australian Bureau of Statistics. (2007). Health of Children in Australia: A Snapshot, 2004-05. [cited 201024 August]; Avail from:

http://www.abs.gov.au/AUSSTATS/abs@.nsf/mf/4829.0.55.001/.

Australian Bureau of Statistics. (2011). Sports and Physical Recreation: A Statistical Overview, Australia, 2011.

http://www.abs.gov.au/ausstats/abs@.nsf/Products/BCEBC1565CADCFA4CA25796B0015 1754?opendocument (Accessed on May 2017).

Bakhos, L.L., Lockhart, G.R., Myers, R., \& Linakis, J.G. (2010). Emergency department visits for concussion in young child athletes. Pediatrics 126(3), pp. e550-e556.

Banas, M.P., Dalldorf, P.G., \& Marquardt, J.D.(1992). Skateboard and in-line skate fractures: A report of one summer's experience. Journal of Orthopaedic Trauma 6(3), pp. 301-305.

Bauer, G., \& Kiefer, H. (1991). A complex forearm injury caused by skateboarding | [Eine komplexe Unterarmverletzung beim Skateboardfahren.]. Sportverletzung Sportschaden : Organ der Gesellschaft fur Orthopadisch-Traumatologische Sportmedizin 5(4), pp. 202-204.

Birkhoelzer, W., Kirschner, P., \& Schweikert, C.H.(1979) Skateboards: A dangerous toy?| [ROLLBRETT - GEFAHRLICHES SPIELZEUG?] Deutsche Medizinische Wochenschrift. 104(10), pp. 345-347

Boyle, W.E. (1995). Skateboard injuries. Pediatrics; 95 (4): 611-2.

Bramley, H., McFarland, C., Lewis, M.M., Shaffer, M.L., Cilley, R., Engbrecht, B., Santos, M., Rzucidlo, S., Shirk, B., Simmons, L., \& Dias, M.S.(2014).Short-term outcomes of sport- and recreation-related concussion in patients admitted to a pediatric trauma service. Clinical Pediatrics 53, 8: 784-790.

Brudvik, C.(2001). Rollerblading and skateboarding injuries in children in Bergen, Norway | [Rulleskøyte- Og rullebrettskader blant barn i Bergen] Tidsskrift for den Norske Laegeforening 121(1), pp. 19-22.

.Campodonico, F. , Paparo, F., Calcagno, T., Capponi, G., 7 Conzi, G. (2016). Renal trauma in adolescent skateboarders. Archivos Espanoles de Urologia; 69, 9: 662-665.

Cass, D.T., \& Ross, F. (1990). Skateboard injuries. Medicine Journal of Australia. 153:140, 143144. 
Cox, G., Thambapillay, S., \& Templeton, P.A. (2008). Compartment syndrome with an isolated Salter Harris II fracture of the distal tibia. Journal of Orthopaedic Trauma. 22(2), pp. 148150.

Dumas, A., \& Laforest, S. (2009). Skateparks as a health-resource: Are they as dangerous as they look? Leisure Studies. 28(1): 19-34.

Determana, J.J, Frederick, E.C., Coxa, J.S., \& Nevitta, M.N. (2010). High impact forces in skateboarding landings affected by landing outcome. Footwear Science. 2;3: 159-170.

Everett, W.W. (2002). Skatepark injuries and the influence of skatepark design: A one year consecutive case series. Journal of Emergency Medicine. 23(3), pp. 269-274.

Falavigna, A., Medeiros, G.S., Canabarro, C.T., Barazzetti, D.O., Marcon, G., Carneiro Monteiro, G.M., Bossardi, J.B., da Silva, P.G., Teles, A.R., Velho, M.C., \& Ferrari, P. (2014) How can we teach them about neurotrauma prevention? Prospective and randomized "Pense BemCaxias do Sul" study with multiple interventions in preteens and adolescents. Journal of Neurosurgery Pediatrics. 14:94-100.

Feletti F. (2016) Extreme Sports Medicine. Editorial, in Feletti F (Ed) Extreme Sports Medicine, Springer 2016. p. vii- viii. doi: 10.1007/978-3-319-28265-7

Feiler, S., \& Frank, M. Skateboarding injuries | [Verletzungsmuster und verletzungsrisiko beim skateboarding] Sportverletzung-Sportschaden. 14(2), pp. 59-64.

Finch, C. (1998). Sport and active recreation injuries in Australia: Evidence from emergency department presentations. British Journal of Sports Medicine. 32(3), pp. 220-225.

Forjuoh SN, Fiesinger T, Schuchmann JA, \& Mason S. (2002) Helmet use. A Survey of 4 Common Childhood Leisure Activities. Archives of Pediatric Adolescent Medicine. 156(7):656-661. doi:10.1001/archpedi.156.7.656

Forsman, L., \& Eriksson, A. (2001). Skateboarding injuries of today. British Journal of Sports Medicine. 35(5), pp. 325-328 DOI: 10.1136/bjsm.35.5.325

Fountain, J.L., \& Meyers, M.C. (1996) Skateboarding injuries. Sports medicine. 22(6):360-366.

Giacobetti, F.B., Sharkey, P.F., Bos-Giacobetti, M.A., Hume, E.L., \& Taras, J.S. (1997).

Biomechanical analysis of the effectiveness of in-line skating wrist guards for preventing wrist fractures. American Journal of Sports Medicine. 25:223-5.

Gomez AT, \& Rao A. (2016) Adventure and Extreme Sports. Medical Clinics of North America, 
Vol. 100, Issue 2: 371-391.

Graham, L.B. (2010). Skate parks as a context for adolescent development. Journal of Adolescent Research. 25, 2: 288-323. doi: https://doi.org/10.1177/0743558409357236 .

Greenwald, R.M., Janes, P.C., Swanson, S.C., \& McDonald, T.R. (1998). Dynamic impact response of human cadaveric forearms using a wrist brace. American Journal of Sports Medicine. 26:825-30.

Hawkins, R.W., \& Lyne, E.D. (1981). Skateboarding fractures The American Journal of Sports Medicine. 9, 2,:99-102DOI: 10.1177/036354658100900205

Hunter, J. (2012). The Epidemiology of Injury in Skateboarding. In Heggie TW, Caine DJ. Epidemiology of Injury in Adventure and Extreme Sports. Medicine of Sport Science. Basel, Kager, 58; 142-157. doi: 10.1159/000338722.

Illingworth, C.M., Jay, A., Noble, D., \& Collick, M. (1978). 225 Skateboard Injuries in Children. Clinical Pediatrics. 17(10), pp. 781-782 DOI: 10.1177/000992287801701012

Immonen, T., Orth, D., Davids, K., Feletti, F., Liukkonen, J., Jaakkola, T., \& Brymer E. (2017). Understanding action and adventure sports participation - An ecological dynamics perspective. Sports Medicine Open; 3(1):18. doi: 10.1186/s40798-017-0084-1 .

Keays, G., Dumas, A. (2014). Longboard and skateboard injuries. Injury. ;45(8):1215-9. doi: 10.1016/j.injury.2014.03.010.

Keilani, M., Krall, C., Lipowec, L., Posch, M., Komanadj, T.S., \& Crevenna, R. (2010).

Skateboarding injuries in Vienna: Location, frequency, and severity. PM and R. 2; 7: 619624. DOI: $10.1016 /$ j.pmrj.2010.04.022

Kellet, P., \& Russell, R. A. (2009). Comparison between mainstream and action sport industries in Australia: A case study of the skateboarding cluster. Sport Management Review. 2009; 12 , 2: 66-78. doi: 10.1016/j.smr.2008.12.003 .

Kern, L., Geneau, A., Laforest, S., Dumas, A., Tremblay, B., Goulet, C., Lepage, S., \& Barnett, T.A. (2014) Risk perception and risk-taking among skateboarders. Saf Sci.;62: 370-375.

Konkin, D.E., Garraway, N., Hameed, S.M., Brown, D.R., Granger, R., Wheeler, S., \& Simons, R.K. (2006). Population-based analysis of severe injuries from nonmotorized wheeled vehicles American Journal of Surgery. 191, 5: 615-618. DOI:

10.1016/j.amjsurg.2006.02.012 
Kyle, S.B., Nance, M.L., Rutherford Jr., G.W., \& Winston, F.K. (2002) Skateboard-associated injuries: Participation-based estimates and injury characteristics. Journal of Trauma - Injury, Infection and Critical Care. 53(4), pp. 686-690.

Knoppert, D., Reed, M., Benavides, S., Totton, J., Hoff, D., Moffett, B., Norris, K., Vaillancourt, R, Aucoin, R,, \& Worthington, M.. (2007) Paediatric age categories for essential medicines for children. First Meeting of the Subcommittee of the Expert Committee on the Selection and Use of Essential Medicines. WHO. Geneva, 9-13 July 2007.

Kumanyika S, Jeffery R, Morabia A, Ritenbaugh C, \& Antipatis V. (2002) Obesity prevention: the case for action. International Journal of Obesity;26:425-36.

Kroncke, E.L., Niedfeldt, M.W.,\& Young C.C. (2008). Use of Protective Equipment by Adolescents in Inline Skating, Skateboarding, and Snowboarding. Clinical Journal of Sport Medicine.18:38-43.

Kruse, P. (1990). Splenic rupture—a skateboard accident. Ugeskr Laeger. 990;152:681.

Kumar S, Herbst B, \& Strickland D. (2012). Experimental biomechanical study of head injuries in lateral falls with skateboard helmet. Biomed Science Instrum;48:239-45.

Lovejoy, S., Weiss, J.M., Epps H.R., Zionts, L.E., \& Gaffney, J. (2012). Preventable Childhood Injuries. Journal of Pediatric Orthoptics;32:736-742.

Lustenberger, T., Talving, P., Barmparas, G., Schnüriger, B., Lam, L., Inaba, K., \& Demetriades, D. (2010) Skateboard-related injuries: Not to be taken lightly. A national trauma databank analysis. Journal of Trauma - Injury, Infection and Critical Care. 69, 4: 924-927 DOI: 10.1097/TA.0b013e3181b9a05a

Macdonald, D.J.M., McGlone, S., Exton, A., \& Perry, S. (2006) A new skatepark: The impact on the local hospital. Injury 37(3), pp. 238-242

McKenzie, L.B., Fletcher, E., Nelson, N.G, Roberts, K.J., \& Klein, E.G. (2016) Epidemiology of skateboarding-related injuries sustained by children and adolescents 5-19 years of age and treated in US emergency departments: 1990 through 2008. Inj. Epidemiol. 3: 10. doi:10.1186/s40621-016-0075-6.

Morgan, W.J., Galloway, D.J.,\& Patel, A.R. (1980) Prevention of skateboard injuries. Scottish Medical Journal 25(1), pp. 39-40. 
Nathanson B., Ribeiro K., \& Henneman PL. (2016) An Analysis of US Emergency Department Visits From Falls From Skiing, Snowboarding, Skateboarding, Roller-Skating, and Using Nonmotorized Scooters Clinical. Pediatrics. 55(8) 738-744. doi: $10.1177 / 0009922815603676$

Norkus, SA., \& Meyers, MC. (1994) Ulnar neuropathy of the elbow. Sports Medicine. 17:189-99.

O’Connor, P. (2016) Skateboarding, Helmets, and Control: Observations from Skateboard Media and a Hong Kong Skatepark. Journal of Sport and Social Issues, 40 (6), pp. 477-498.

Osberg, J.S., Schneps, S.E., Di Scala, C., \& Li, G. (1998) Skateboarding: More dangerous than roller skating or in-line skating. Archives of Pediatrics and Adolescent Medicine. 152(10), pp. 985-991.

Outdoor Foundation. (2013). Outdoor Participation Report 2013 (PDF file). Available from http://www.outdoorindustry.org/images/ researchfiles/ParticipationStudy2013.pdf?193. Accessed 31 May 2017.

Patel DR., Greydanus DE., \& Baker RJ. (2009) Pediatric practice: sports medicine. New York, NY: McGraw Hill;

Peachey, A.A., Sutton, D.L., \& Cathorall, M.L. (2016). Helmet ownership and use among skateboarders: Utilisation of the Health Belief Model. Health Education Journal 75(5): 565576.

Pendergrast Jr., R.A.(1990). Skateboard injuries in children and adolescents. Journal of Adolescent Health Care 11(5): 408-412.

Rethnam, U., Yesupalan, R.S., \& Sinha, A. (2008). Skateboards: Are they really perilous? A retrospective study from a district hospital. BMC Research Notes 1,59.

Retsky, J., Jaffe, D., \& Christoffel, K. (1991). Skateboarding Injuries in Children: A Second Wave. American Journal of Diseases of Children 145(2): 188-192.

Roberts D. J., Ouellet J., McBeth P.B, Kirkpatrick A.W., Dixon E., \& Ball C.G. (2014) The "weekend warrior": Fact or fiction for major trauma? Canadian Journal of Surgery. 57(3): E62-E68.

Sadeghian H, Nguyen, B, Huynh, N, Rouch, J, Lee, S L, \& Bazargan-Hejazi, S. (2017). Factors Influencing Helmet Use, Head Injury, and Hospitalization Among Children Involved in Skateboarding and Snowboarding Accidents. Perm Journal. 21(16), 161. 
Schalamon J, Sarkola T, \& Nietosvaara Y. (2003) Injuries in children associated with the use of nonmotorized scooters._Journal of Pediatric Surgery. 38(11):1612-5.

Schmid, A., \& Rotzscher, V.(1993)Pattern of injuries in skateboard accidents. Unfallchirurg. 96:641- 644 .

Schuman, S.H. (1967). Skateboard Injuries in a Campus Community. Clinical Pediatrics 6; (4) 252254.

Shuman, K.M., \& Meyers, M.C. (2015). Skateboarding injuries: An updated review. Physiological Sportsmed, Early Online: 1-7. doi: 10.1080/00913847.2015.1050953

Sheehan, E., Mulhall, K.J., Kearns, S., O'Connor, P., McManus, F., Stephens, M., \& McCormack, D. (2003). Impact of dedicated skate parks on the severity and incidence of skateboard- and rollerblade-related pediatric fractures. Journal of pediatric orthopedics. 23(4): 440-442.

Stracciolini, A., Casciano, R., Friedman, H.L., Meehan, W.P., \& Micheli, L.J. (2015). A closer look at overuse injuries in the pediatric athlete. Clinical Journal of Sport Medicine. 25(1), pp. 3035 .

Swischuk, L.E. (2015) Musculoskeletal: what's different in children? Left arm pain after fall during skateboarding. Emergency Radiology. 22 (Suppl 1):S9-S10 DOI 10.1007/s10140-014-11971

Tator CH (2008) Catastrophic Injuries in Sports and Recreation: Causes and Prevention. A Canadian Study. Toronto, University of Toronto Press,

Thorpe, H. (2016). Action sports for youth development: critical insights for the SDP community. International Journal of Sport Policy and Politics. 8 (1), 91-116.

Tominaga, G.T., Schaffer, K. B., Dandan, I.S., Coufal, F.J., \& Kraus J. F. (2015). Head injuries in hospital-admitted adoscents and adults with skateboard-related trauma. Brain. Injury. 29(9):1044-1050.

Vaca, F., Mai, D., Anderson, C.L., Fox, J.C., \& Ferrarella, N. (2007).Associated economic impact of skatepark-related injuries in Southern California. Clinical Medicine and Research. 5(3): $149-154$

West, T. A., \& Marion, D. W. (2014). Current Recommendations for the Diagnosis and Treatment of Concussion in Sport: A Comparison of Three New Guidelines. Journal of Neurotrauma, 31(2), 159-168. http://doi.org/10.1089/neu.2013.3031 
Zalavras, C., Nikolopoulou, G., Essin, D., Manjra, N., \& Zionts, L.E. (2005). Pediatric fractures during skateboarding, roller skating, and scooter riding. American Journal of Sports Medicine 33(4), pp. 568-573. DOI: 10.1177/0363546504269256 